[ 원 저

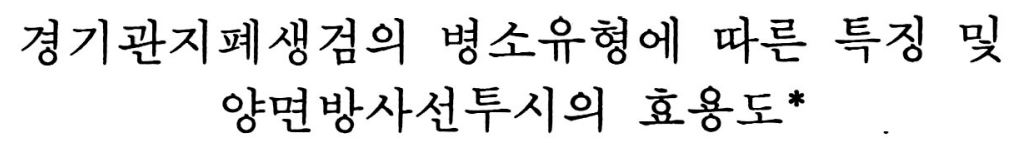

서울대학교 의과대학 내과학교실 및 결핵연구소

현인규・정희순·김우성·정만표

한성구 • 심영수 · 김건열・한용철

$=$ Abstract $=$

\title{
Characteristics of TBLB According to the Type of Pulmonary Lesion and Diagnostic Validity of Biplane-Fluoroscopy in TBLB
}

In Gyu Hyun, M.D., Hee Soon Chung, M.D., Woo Sung Kim, M.D.

Man Pyo Jeong, M.D., Sung Koo Han, M.D., Young Soo Shim, M.D.

Keun Youl Kim, M.D., and Yong Chol Han, M.D.

Department of Internal Medicine \& Tuberculosis Research Institute, College of Medicine, Seoul National University, Seoul, Korea

TBLB (transbronchial lung biopsy) is well-known as a valuable and relatively safe diagnostic tool in both diffuse and localized lesion which is invisible on routine bronchoscopy. To investigate the diagnostic validity of biplane-fluoroscopy in TBLB of diffuse lesion and the diagnostic rate of TBLB according to the size of localized lesion, we analyzed 105 cases (54 cases of diffuse lesion and 51 cases of localized lesion) of TBLB.

In diffuse pulmonary lesion, diagnostic rate of TBLB under the fluoroscopic guide was $85.7 \%$ and that of blind biopsy was $78.9 \%$. The incidence of pneumothorax as complication of TBLB was $5.7 \%$ with fluoroscopy, and $5.3 \%$ without it. Between the presence and the absence of fluoroscopy, there was no significant difference $(p>0.05)$ in the rates of diagnosis and complication of TBLB. When TBLB was performed at anterobasal segment of lower lobe, the diagnostic rate was significantly high $(\mathrm{p}<0.01)$. In localized pulmonary lesion, the diagnostic rate of TBLB was $70.6 \%$ and the diagnostic yield significantly increased $(p<0.01)$ when the size of lesion was $3 \mathrm{~cm}$ or more. Pneumothorax was found in only $2.0 \%$.

It can be concluded that biplane-fluoroscopy isn't an absolute prerequisite for TBLB and the diagnostic rate might be maximized when TBLB is done at anterobasal segment of lower lobe in diffuse pulmonary lesion. And it is anticipated that the diagnostic yield of TBLB is better when the diameter of lesion is $3 \mathrm{~cm}$ or more in localized disease.

서 론

폐를 침범하는 질환이 다양한 만큼 원인질환을 규명한

*본.논문의 요지는 대한 결핵 및 호흡기학희 제 67 차 추계

학술대회에서 발표 되었으며, 1989년도 서울대학병원

특진연구비의 보조로 이루어 졌음.
다는 것도 쉬운 문제가 아닌데, 이를 위해서는 목표가 되는 폐조직을 얻어야 할 때가 많다. 폐조직을 얻는 방 법으로는 개훙폐생검 (open lung biopsy) ${ }^{1,2)}$, 경피침흡 입법 (percutaneous needle aspiration) ${ }^{3 \sim 5)}$ 그리고 굴 곡성기관지경을 통한 경기관지폐생검 (transbronchial lung biopsy) 등6 9)이 흔히 이용되고 있는데, 개훙폐생 검은 환자에게 부담이 될 뿐만 아니라 인력이나 설비면 
에서도 제약점이 있으며 경피침흡입법은 생검법이라기 보다는 세포진법에 가까우므로 양성질환의 감별진단이 어렵고 악성질환에서는 조직생검에 의한 진단과 세포형 이 일치하지 않는 경우가 상대적으로 많다미. 그러나 경 기관지폐생검은 환자의 부담이 적고 진단의 정확도나 진 단율도 높으며 합병증도 비교적 적은 방법이라고 할 수 있는데, 병소의 유형 (미만성 혹은 국한성)이나 크기, 기 관지경시술자의 숙련정도 등에 따라 진단율에 차이가 많 고 일반적으로 양면방사선투시 (biplane fluoroscopy) 를 필요로 한다는 단점도 갖고 있다.

경기관지폐생검을 시행할 때 국한성 병변인 경우 병소 에서 조직을 직접 채취하기 위해서는 양면방사선투시가 필수적이며 크기가 어느정도 이상이 되어야 병소에 접근 하기가 용이하겠지만, 미만성 병변인 경우에도 양면방 사선투시가 필수적이냐 하는 데에는 논란이 있을 수 있 다. 저자들은 경기관지폐생검에서 진단율, 병소의 유형 과 원인질환에 따른 진단율의 차이, 합병증의 빈도를 알 아보고, 미만성 병변의 경우 생검시 양면방사선투시의 효용도, 그리고 국한성 병변에서 병소의 크기에 따른 진 단율의 차이 등을 검토하고자 본 연구를 시행하였다.

\section{대상 및 방법}

\section{1. 대 상}

서울대학병원 내과에 입원한 환자중 단순흥부방사선 검사에서 미만성침윤이나 폐결절을 보이고 기관지경검 사상 가시병변이 없어서 원인질환을 규명하고자 경기관 지폐생검을 시행했던 105예를 대상으로 하였다.

\section{2. 방 법}

\section{1) 경기관지폐생검법}

혈액응고검사, 심전도검사, 폐기능검사 등의 기초검 사상 기관지경검사에 대한 금기사항이 없음을 확인하였 으며, atropine $0.5 \mathrm{mg}$ 과 meperidine $50 \mathrm{mg}$ 으로 전처 치하고 국소마취하에 Olympus의 BF-2T 10 기관지경 과 $\mathrm{FB}-20 \mathrm{C}$ 생검겸자를 사용하여 경기관지폐생검을 시 행하였다.

미만성 병변의 경우 양면방사선투시를 무작위로 사용 하여 폐의 하엽에서 생검을 시행하였는데, 홍벽에 의한 저항이 느껴질 때까지 생검겸자를 삽입하였다가 $2 \mathrm{~cm}$ 정도 후퇴하여 환자가 최대로 흡기한 상태에서 겸자를
개방시키고 호기후에 생검겸자를 다시 $1 \sim 2 \mathrm{~cm}$ 전진시 켜 환자에게 홍통이 없음을 확인하고 조직을 채취하는 방법으로 최소한 4회 이상이 생검을 반복시행하였다.

국한성 병변에서는 홍부방사선사진을 검토하여 병소 의 위치를 예측한 다음에 양면방사선투시하에서 생검겸 자를 삽입하여 병소에 적중되는가를 확인하였고, 겸자 로 병소의 조직을 잡은 상태에서 환자가 기침할 때 겸자 와 병소가 같이 움직이는 것을 방사선투시로 관찰하고 4 회 이상의 생검을 시행하였다.

\section{2) 경기관지폐생검으로 인한 합병증의 확인}

기관지경검사시 생검으로 인한 출혈이 지혈된 다음에 검사를 종료하였으며, 검사후에는 홍통이나 호홉곤란 등의 주관적 증상의 유무를 확인하였고 향부방사선검사 로 기흥 및 폐출혈의 발생여부를 조사하였다.

\section{3) 자료분석}

미만성 병변에서는 원인질환에 따른 경기관지폐생검 의 진단율을 산출하고 방사선투시의 사용여부에 따라 진 단율 및 합병증발생율이 달라지는가를 chi-square test (유의수준 $95 \%$ )로 비교하였으며, 국한성 병변에서는 원인질환과 병소의 크기에 따른 경기관지폐생검의 진단 율을 검토하였다.

\section{결 과}

105 예의 경기관지폐성검중 미만성 병변은 54 예였으 며, 국한성 병변은 51예였다.

\section{1. 미만성 병변}

조직학적 진단을 얻은 경우가 45 예로 $83.3 \%$ 의 진단 율을 보였는데, 특발성 폐섬유증 (idiopathic pulmonary fibrosis ; IPF) 이 21예 (38.9\%), 속립성폐결핵이 17예 (31.5\%), 악성종양의 미만성폐전이가 6예 $(11.1 \%)$, 폐포단백증 (pulmonary alveolar proteinosis ; PAP) 이 1 예 (1.8\%) 였다. 그리고 질병별로는 특발성폐섬유증 이 $87.3 \%$ (24예중 21 예), 속립성폐결핵이 $100.0 \%$ (17 예 전예), 악성종양의 미만성 폐전이가 $66.7 \%$ (9예중 6 예), 폐포단백증이 $100.0 \%$ (1예), 의 진단율을 보였다 (Table 1). 경기관지폐생검으로 진단되지 않은 9예 (16.7\%) 중 7 예는 객담검사나 개훙폐생검 등으로 진단 이 확정되었는데 특발성폐섬유증 및 악성질환의 폐전이 가 각각 3 예씩 이었고 1 예는 폐국균증(pulmonary 
Table 1. Diagnostic Yield of TBLB According to Specific Diagnosis in Diffuse Pulmonary Lesion

\begin{tabular}{lcc}
\hline \hline & No. of cases & $\begin{array}{c}\text { No. of positive } \\
\text { Dx (\%) }\end{array}$ \\
\hline I P F & 24 & $21(87.3)$ \\
Miliary Tbc & 17 & $17(100.0)$ \\
Cancer dissemination & 9 & $6(66.7)$ \\
P A P & 1 & $1(100.0)$ \\
Aspergillosis & 1 & $0(0.0)$ \\
Unknown & 2 & --- \\
\hline Total & 54 & $45(83.3)$ \\
\hline
\end{tabular}

Table 2. Diagnostic Yield and Complication-rate of TBLB in Relation to Biplane-Fluoroscopy in Diffuse Pulmonary Lesion

\begin{tabular}{lcc}
\hline \hline & $\begin{array}{c}\text { Fluoroscopy- } \\
\text { guided Bx }\end{array}$ & Blind Bx \\
\hline No. of cases & 35 & 19 \\
No. of positive Dx (\%) & $30(85.7)$ & $15(78.9)^{*}$ \\
No. of Complication (\%) & $2(5.7)$ & $1(5.3)^{*}$ \\
\hline
\end{tabular}

*; not-significantly different $(p>0.05)$

aspergillosis)이었으며, 2예에서는 환자의 거부로 최종 진단을 얻지 못하였다.

양면방사선투시를 사용했던 35예에서는 $85.7 \%$ 그리 고 방사선투시없이 맹검을 시행한 19예에서는 $78.9 \%$ 의 진단율을 얻었고 합병증으로는 기흥이 각기 $5.7 \%$ 및 $5.3 \%$ 에서 발생하였는데, 두가지 모두 통계적으로 유의 한 차이는 없었다(Table 2).

참고로 생검부위를 살펴보면 하엽의 전기저 (anterobasal) 엽이 44예 (81.5\%), 외기저(laterobasal) 엽 이 8 예 (14.8\%), 후기 저 (posterobasal)엽 이 2예 $(3.7 \%)$ 로서, 진단율은 각각 $90.9 \%, 37.5 \%$ 및 $50.0 \%$ 였다(Table 3).

\section{2. 국한성 병변}

조직학적으로 진단이 가능하였던 경우는 36 예로 진단 율을 $70.6 \%$ 였으며, 질병별로는 폐종양이 17 예 (33.3\%), 결핵성육아종이 16 예 (31.4\%) 그리고 진폐 증, '기질화폐염 및 폐경색증이 1 예 $(2.0 \%)$ 씩이었다. 질 병별 진단율은 폐종양이 $73.9 \%$ (23예중 17 예), 폐결핵 이 $80.0 \%$ (20예중 16 예), 진폐증이 $33.3 \%$ (3예중 1
Table 3. Diagnostic Yield According to the Site of TBLB in Diffuse Pulmonary Lesion

\begin{tabular}{lcc}
\hline \hline & No. of cases & $\begin{array}{c}\text { No. of positive } \\
\text { Dx (\%) }\end{array}$ \\
\hline Anterobasal segment & 44 & $41(90.9)^{*}$ \\
Laterobasal segment & 8 & $3(37.5)^{*}$ \\
Posterobasal segment & 2 & $1(50.0)^{*}$ \\
\hline$*$; significantly different $(p<0.01)$ &
\end{tabular}

Table 4. Diagnostic Rate of TBLB According to Specific Disease in Localized Pulmonary Lesion

\begin{tabular}{lcc}
\hline \hline & No. of cases & $\begin{array}{c}\text { No. of positive } \\
\text { Dx }(\%)\end{array}$ \\
\hline Lung cancer & 23 & $17(73.9)$ \\
Squamous & 10 & $9(90.0)$ \\
Adeno. & 9 & $5(55.6)$ \\
Alveolar & 4 & $3(75.0)$ \\
Tbc granuloma & 20 & $16(80.0)$ \\
Pneumoconiosis & 3 & $1(33.3)$ \\
Organizing pneumonia & 2 & $1(50.0)$ \\
Pu'monary infarct & 1 & $1(100.0)$ \\
Paragonimiasis & 1 & $0(0.0)$ \\
Unknown & 1 & --- \\
\hline Total & 51 & $36(70.6)$ \\
\hline
\end{tabular}

예), 기질화폐염이 $50.0 \%$ (2예중 1예), 폐경색증이 $100.0 \%$ ( 1 예) 였으며, 폐흡중증 1 예는 경기관지폐생검 으로 진단되지 않았고 최종진단을 얻지 못한 경우도 1예 가 있었다. 폐종양 23 예의 세포형을 살펴보면 편평상피 암이 10예 (43.5\%), 선암이 9예 (39.1\%), 폐포세포암 이 4 예 $(17.4 \%)$ 였는데, 경기관지폐생검에 의한 진단율 은 각각 $90.0 \%, 55.6 \%$ 및 $75.0 \%$ 였다(Table 4 ).

병소의 크기에 따라 $2 \mathrm{~cm}$ 미만, $2 \sim 3 \mathrm{~cm}, 3 \sim 4 \mathrm{~cm}$, 4 $5 \mathrm{~cm}$ 그리고 $5 \mathrm{~cm}$ 이상의 병변으로 나누어보면 진단 율을 각기 $60.0 \%, 58.8 \%, 78.6 \%, 75.0 \%$ 및 $85.7 \%$ 였으며 (Table 5), 1 예 (2.0\%)에서만 합병증으로 기훙 이 관찰되었다.

\section{고 찰}

\section{1. 경기관지폐생검의 진단율}

경기관지폐생검은 1965년에 Andersen등이 고형기관 
Table 5. Diagnostic Rate of TBLB According to the Size of Localized Pulmonary Lesion

\begin{tabular}{ccc}
\hline \hline Diameter of lesion & No. of cases & $\begin{array}{c}\text { No. of positive } \\
\text { Dx (\%) }\end{array}$ \\
\hline less than $2 \mathrm{~cm}$ & 5 & $3(60.0)$ \\
$2-3 \mathrm{~cm}$ & 17 & $10(58.8)$ \\
\hline less than $3 \mathrm{~cm}$ & 22 & $13(59.1)^{*}$ \\
\hline $3-4 \mathrm{~cm}$ & 14 & $11(78.6)$ \\
$4-5 \mathrm{~cm}$ & 8 & $6(75.0)$ \\
$5 \mathrm{~cm}$ or more & 7 & $6(85.7)$ \\
\hline $3 \mathrm{~cm}$ or more & 29 & $23(79.3)^{*}$ \\
\hline
\end{tabular}

*; significantly different on the margin of $3 \mathrm{~cm}$ $(p<0.01)$

지경음 통하여 최초로 시도하였으며6), Ikeda등이 굴곡 성기관지경을 개발한 이후 보편적인 진단수기로 정착되 었다 ${ }^{11217)}$. 대상환자의 선택과 진단의 기준에 따라 경기 관지폐생검의 진단율이 달라지겠지만 전체적으로 $41 \sim 81 \%^{18 \sim 22)}$, 병소의 유형별로는 미만성 병변이 $61 \sim 91 \% \%^{23 \sim 25)}$ 그리고 국한성 병변이 $56 \sim 81 \%^{18,22,26,27)}$ 의 진단율을 보인다고 보고되어 있는데, 본 연구에서의 경기관지폐생검의 진단율 $77.1 \%$ 도 위와 유사한 결과이 지만 최근 본원에서의 가시병변의 기관지경적 생검진단 율 $86.4 \%$ 보다는 ${ }^{10)}$ 다소 낮은 진단율을 보였다.

\section{2. 미만성 병변의 경기관지폐생검}

미만성 병변에서 특정질환의 진단도 중요하지만 특발 성폐섬유증, 속립성폐결핵 그리고 악성종양의 미만성폐 전이가 차지하는 비중이 $92.6 \%$ 나 된다는 사실에 유념할 필요가 있다. 즉 홍부방사선검사상 미만성 병변이 관칠 되면 우선은 이러한 세가지 질환을 감별진단해야 하며, 경기관지폐생검으로 특발성폐섬유증을 진단할 수 있는 가하는 문제는 차치하더라도 속립성폐결핵 및 악성종양 의 미만성폐전이를 배제하기 위해서도 경기관지폐생검 은 필요하다고 하겠다. 그리고 특발성폐섬유증의 진단 이 경기관지폐생검만으론 불가능하다해도 임상상, 이학 적 소견, 방사선검사 및 기관지폐포세척검사 등의 소견 과 경기관지폐생검에 의해 적절히 채취되어서 유능한 병 리학자에 의해 판독된 조직소견을 종합하면 특발성폐섬 유증의 진단이 전혀 불가능한 것은 아니라고 생각된다.

Andersen등이 방사선투시없이 $2 \times 4 \mathrm{~mm}$ 생검겸자를
사용해서 450 예의 경기관지폐생검을 시행하여 $14 \%$ 의 기홍발생을 보고한 이래 ${ }^{7)}$ 생검으로 인한 기훙을 줄이기 위하여 방사선투시와 $1.5 \times 2 \mathrm{~mm}$ 의 생검겸자가 통상적 으로 사용되어 왔으나, 방사선투시 없이 Joyner등은 37 예의 경기관지폐생검을 시행하여 $76 \%$ 의 진단율과 $2.7 \%$ 의 기홍발생을 보고하였으며 ${ }^{31)} \mathrm{Puar}$ 등도 유육종 증 67 예에서 $76 \%$ 의 진단율과 $1.5 \%$ 의 기훙발생을 ${ }^{32)}$ 그 리고 Prigogine등은 $55 \%$ 의 진단율과 $2.3 \%$ 의 기홍발생 을 ${ }^{33)}$ 각각 보고하였다. 더구나 Anders등은 경기관지폐 생검시 방사선투시를사용한 112예와 사용하지 않은 135 예를 비교하여 미단성 병변에서는 방사선투시의 사용여 부에 따라 진단율이나 합병증발생율에 차이가 없다고 주 장하였다 ${ }^{34)}$. 본 연구에서도 방사선투시를 사용하여 경 기관지폐생검을 하면 방사선투시없이 맹검을 시행할 때 보다 다소 높은 진단율을 보이긴 했지만 통계적 유의성 은 없었고 합병증발생율에도 차이가 없었으므로, 미만 성 병변에서는 방사선투시가 경기관지폐생검에서 필수 적인 절대조건은 아니라고 생각된다. 그러나 가능하다 면 방사선투시를 사용하여 생검겸자의 운동이나 위치를 직접보면서 폐생검을 시행하는 것은 합리적인 방법임에 틀림없다.

생검부위별로 경기관지폐생검의 진단율을 살펴보면 전기저엽에서 가장 높은 진단율을 보이는데, 그 이유는 폐엽의 분포양상에서 추정해볼 수 있다. 즉 전기저엽은 하엽중 차지하는 비중이 상대적으로 크고 외측훙벽에 대 한 접촉면도 넓어서 생검겸자를 삽입할 때 홍벽에 의한 저항이 쉽게 느껴지므로 생검겸자를 충분히 깊게 삽입할 수 있고 그만큼 폐포조직을 채취할 확률이 높아: 기기 때 문이다. 이러한 사실은 경기관지폐생검을 시행할 때 방 사선투시로 쉽게 확인할 수 있는데, 외기저엽이나 후기 저엽에서는 겸자를 깊이 삽입해도 겸자가 횡경막에 접촉 되어 홍벽에 의한 저항이 별로 느겨지지 않으므로 생검 겸자를 적절한 위치까지 삽입하기가 어려워 진단율도 떨 어진다고 생각된다. 그렇기 때문에 본 연구에서는 전기 저엽에서 생검을 시행한 경우가 압도적으로 많은 것이 다.

\section{3. 국한성 병변에서의 경기관지폐생검}

국한성 병변중 폐종양 및 결핵성육아종이 $84.3 \%$ 를 차 지하므로 (Table 4), 방사선검사상 폐결절이 관찰되면 이러한 두가지 질환의 감별진단이 가장 중요하겠다. 국 
한성 병변에서 폐종양이 전체적인 진단율이 $73.9 \%$ 이고 특히 선암의 경우에는 진단율이 $55.6 \%$ 에 불과하므로, 경기관지폐생검에 의해 폐결절이 조직학적으로 진단되 지 않았다면 경피침홉입법 등의 또다른 진단수기를 적용 할 필요가 있다.

결핵성육아종의 경우 경기관지폐생검으로 진단되지 않은 것은 병소의 크기가 $3 \mathrm{~cm}$ 미만이었으며 그 이상의 결핵성육아종은 모두 진단되었던 것처럼 국한성 병변에 서는 병소의 크기에 의해 경기관지폐생검의 진단율이 좌 우되는데, Ellis등은 $4 \mathrm{~cm}$ 미만에서 $58 \%, 4 \mathrm{~cm}$ 이상에 서 $81 \%{ }^{22)}$, Radke등은 $2 \mathrm{~cm}$ 미만에서 $28 \%, 2 \mathrm{~cm}$ 이상 에서 $64 \%{ }^{26)}$ 의 진단율을 보고하였으며 손등은 $3 \mathrm{~cm}$ 미 만에서 $36 \%, 3 \mathrm{~cm}$ 이상에서 $75 \%{ }^{18)}$ 의 진단율을 보고하 였다. 본 연구에서도 $3 \mathrm{~cm}$ 이상의 병소에서 높은 진단 율을 보였는데, 병소의 크기가 어느 정도는 되어야 생검 시 목표물이 적충될 수 있기 때문이다. 그리고 상엽의 후소분절과 하엽의 상소분절간에, 우중엽의 외소분절 혹은 좌설 (lingular)엽의 하소분절과 하엽의 전기저엽 간에서는 양면방사선투시로 확인한 병소의 위치가 훙부 방사선사긴에서 예측한 위치와 일치하지 않는 경우가 종 종있었으며, 특정질환의 폐엽별 분포양상에서는 특기할 만한 사항이 발견되지 않앖다.

\section{4. 경기관지폐생검의 합병증}

기홍, 출혈 및 발열이 주된 합병증이고 드물게는 부정 맥, 감염, 사망 등도 있을 수 있는데, 5.450예의 경기 관지폐생검을 대상으로 한 Suratt의 보고에 의하면 기홍 은 $3.8 \%, 50 \mathrm{cc}$ 이상의 출혈은 $1.2 \%$, 사망이 $0.24 \%$ 에 서 확인되어 합병증의 전체빈도는 $5.3 \%$ 혔였. 본 연구 에서는 105 예중 4 예 $(3.8 \%)$ 에서 기홍이 발생하였는데 모두 $10 \%$ 미만의 경한 기홍으로 산소흡입 및 안정만으로 치유되었으며, 폐출혈이나 기타 합병증이 관찰된 경우 는 없었다.

\section{결 론}

양면방사선투시가 미만성 병변의 경우 경기관지폐생 검의 진단율이나 합병증발생율에 큰 영향을 미치지 못하 므로 경기관지폐생검에서 방사선투시가 필수적인 조건 은 아니며, 생검이 기술적으로 용이한 폐하엽의 전기저 엽에서 생검을 시행할 때 비교적 높은 진단율이 기대된
다. 그리고 국한성 병변에서는 병소의 크기가 $3 \mathrm{~cm}$ 이 상이면, 경기관지폐생검에 의해 정확한 진단을 얻을 가 능성이 상대적으로 높을 것이다.

\section{REFERENCES}

1) Gaensler EA, Moister VB, Hamm J: Open lung biopsy in diffuse pulmonary disease. $\mathrm{N}$ Engl J Med 270:1319, 1964

2) Ray III JF, Lawton BR, Myers WO, Toyama WM, Reye CN, Emanuel DA, Burns JL, Pederson DP, Do: enberger WV, Wenzel EJ, Sautter RE: Open lung biopsy. Chest 69:43, 1976

3) Mark JB, Marglin SI, Ellis JH: The role of bronchoscopy and needle aspiration in the diagnosis of peripheral lung cancer. J Thoracic Cardiovasc Surg 76:266, 1978

4) Sinner WN: Transthoracic needle biopsy of small peripheral malignant lung lesion. Invest Radiol 8: 305, 1973

5) Wallance JM, Deutsch AC: Flexible fiberoptic bronchoscopy and percutaneous needle lung aspiration for evaluation the solitary pulmonary nodule. Chest 81:665, 1982

6) Andersen HA, Fontana RS, Harrison EG: Transbronchial lung biopsy in diffuse lung disease. Dis Chest 48:187, 1965

7) Andersen HA, Fontana RS: Transbronchial biopsy for diffuse pulmonary disease. Chest 62:125, 1972

8) Ikeda S: Flexible fiberoptic bronchoscope. Ann Otol Rhnol Laryngol 79:916, 1970

9) Levin DC, Kick AB, Ellis JH: Transbronchial biopsy via the fiberoptic bronchoscope. Am Rev Respir Dis 110:4, 1974

10). 정희순, 유 빈, 김현태, 기만덕, 한성구, 심영수, 김 건열, 하용철 : 폐암에서 각종 진단수기의 진단율에 대한 연구. 대한내과학회잡지 $33: 3,1987$

11) 이종현, 문영주, 박일주, 서복주, 손창학, 김인재 : 기곤지내시경 검사에 의한 각종 폐질환의 진단적 가 치. 대한내과학회잡지 20:617, 1977

12) 김계방, 김진우, 김원동 : 굴곡성 기관지경의 임상적 이용에 관한 경험. 대한내과학회잡지 $33: 210,1979$

13) 윤영숙, 김기완, 신우종, 김국룡, 이종현 : 기관지경 검사 671예에 대한 각종 폐질환의 진단적 가치 및 임 상적 고찰. 결핵 및 호홉기질환 $28: 19,1981$

14) 김성규, 이원영, 김기.호, 박찬일 : Transbronchial lung biopsy의 진단적 의의. 대한내과학회잡지 24 : 
413, 1981

15) 김원동 : 경기관지법에 의한 폐질환의 진단. 대한내과 학회잡지 25:617, 1982

16) 박준호, 이인균, 정병천, 김시석, 전영균, 이정규: 경기관지법에 의한 폐질환의 진단. 대한내과학희잡지 28:841, 1985

17) 이국희, 김교선, 손명원, 유덕종, 이원식, 정태훈 : 경기관지페생검의 진단적 가치. 대한내과학회잡지 30 : 154,1986

18) 손희영, 조철호, 장 준, 안철민, 김성규, 이원영, 김 기호 : 폐질환의 진단에 있어 경기관지 폐생검의 활용 에 관한 연구. 대한내과학회잡지 $31: 289,1986$

19) Cortese DA, McDougall JC: Biopsy and brushing of peripheral lung cancer with fluoroscopy guidance. Chest 75:141, 1979

20) Fennesy JJ: Transbronchial biopsy of peripheral lung lesion. Radiology 88:838, 1967

21) Andersen HA: Transbronchial lung biopsy for diffuse pulmonary disease. Chest 73:734, 1978

22) Ellis JH, Jr: Transbronchial lung biopsy via the fiberoptic bronchoscope. Chest 68:524, 1975

23) Stableforth RK: Transbronchial lung biopsy through the fiberoptic bronchoscope. Br J Dis Chest 72:108, 1978

24) Koerner SK, Sakowiz AJ, Appleman RI, Boeker NH, Schoenbaum SW: Transbronchial lung biopsy for the diagnosis of sarcoidosis. N Engl J Med 293: 268, 1975

25) Mitchell DM, Emerson CJ, Collyer J: Fiberoptic bronchoscopy, Br Med J 281:360, 1980

26) Radke JF, Conway WA, Eyler WR, Kavle PA: Diagnostic accuracy in peripheral lung disease. Chest 76:176, 1979

27) Zavala DC: Diagnostic fiberoptic bronchoscopy: Technique and results of biopsy in 600 patients. Chest 68:12, 1975

28) Hooper RG, Tellis CJ, Hunt KK: Methodology in transbronchial lung biopsy. [Correspondance] Chest 72:130, 1972

29) Zavala DC: Methodology in transbronchial lung biopsy. [Letter] Chest 72:130, 1972

30) Zavala DC: Transbronchial biopsy in diffuse lung disease. Chest 73:727, 1978

31) Joyner LR, Scheinhorn DJ: Transbronchial forceps lung biopsy through the fiberoptic bronchoscope. Chest 67:532, 1975

32) Puar HS, Young RC, Armstrong EM: Bronchial and transbronchial lung biopsy without fluoroscopy in sarcoidosis. Chest 87:303, 1985

33) Prigogine $T$, Schmerber J: Transbronchial lung biopsy without fluoroscopy [Letter] Chest 92:187, 1987

34) Anders GT, Johnson JE, Bush BA, Matthwes JI: Transbronchial biopsy without fluoroscopy-a seven year perspective. Chest 94:557, 1988

35) Suratt PM, Herf SM, Arora NS: Deaths and complications associated with transbronchial lung biopsy. Am Rev Respir Dis 115:708, 1977 